\title{
KẾT QUẢ PHẪU THUÂTT THAY KHỚP BÁN PHẦN ĐIỀU TR! GÃY LIÊN MẤU CHUYỂN XƯƠ'NG ĐÙI Ở NGƯờI CAO TUỔI
}

\section{TÓM TẮT}

Gãy liên mấu chuyển xương đùi (LMCXĐ) là loại gãy thường gặp, đặc biệt là người cao tuổi. Điêu tị gãy LMCXĐ phụ thuộc loại gãy, chất lượng xương và thể trang người bênh. Mục tiêu: Đánh giá kết quả phẫu thuật thay khớp bán phần điều trị gãy LMCXĐ người cao tuổi. Phương pháp: Nghiên cứu mô tả cắt ngang 50 bệnh nhân gãy $L M C X \boxminus$ kiểu $A_{1}$ và $A_{2}$, có độ tuổi trung bình là 80,7 tuổi, tỷ lệ nữ/nam là $2 / 1$. Kết quả: rất và tốt đạt $84 \%$, khá đạt $12 \%$, trung bình và xấu 4\%. Phẫu thuật thay khớp háng bán điều trị gãy LMCXĐ là một phương pháp tốt cho người già, giúp sớm vận động trở laị.

Từ khóa: Gãy LMCXĐ, thay khớp háng bán phân

\section{SUMMARY}

\section{THE RESULT OF PARTIAL HIP REPLACEMENT FOR INTERTROCHANTERIC FRACTURE IN ELDER PATIENTS}

The intertrochanteric fracture is quite common, especially in elder patients. Objective: Evaluate the result of partial hip replacement for intertrochanteric fracture in elder patients. 50 patients with average age is 80,7 years old, female/male ratio is $2 / 1$. The results of surgery is: $84 \%$ good, $12 \%$ moderate and $4 \%$ is bad. Hemi-hip replacement for transtrochanteric fracture is the good surfical treatment for old osteoporosis patient.

Keywords: intertrochanteric fracture, Partial hip replacement

\section{I. ĐăTT VẤN ĐỀ}

Gãy LMCXĐ khá phổ biến, chiếm $55 \%$ các loại gãy đầu trên xương đưi, $95 \%$ gặp ở người cao tuổi, phụ nữ gặp nhiều gấp 2-3 lần nam giới.

Gãy LMCXĐ có tần xuất tăng theo tuổi thọ, người già sức khỏe yếu và bị loãng xương nên chỉ ngã đập mông xuống nền cứng với một lực nhẹ có thể gãy xương.

Điều trị gãy LMCXĐ điều trị bằng phương pháp điều trị bảo tồn hoặc điều trị phẫu thuật. Trước kia, phương pháp điều trị bảo tồn được sử dụng nhiều với phương pháp bất động bằng bó bột hoặc xuyên kim kéo liên tục nhưng thời gian điều trị lâu, bệnh nhân gặp nhiều biên chứng và

\footnotetext{
${ }^{1}$ Trường Đại Học Y Hà Nội

²Bệnh viện HN Việt Đức

Chịu trách nhiệm chính: Dương Đình Toàn

Email: duongdinhtoan@hmu.edu.vn

Ngày nhận bài: 10.5.2021

Ngày phản biện khoa học: 30.6.2021

Ngày duyệt bài: 9.7.2021
}

Dương Đình Toàn ${ }^{1,2}$

tỷ lệ tử vong cao do các bệnh toàn thân. Ngày nay với tiến bộ cuả trang thiết bị, kỹ thuật ngoại khoa và hồi sức nên chỉ định điều trị phẫu thuật ngày càng mở rộng, làm giảm thời gian điều trị, tử vong và nâng cao chất lượng sốngngười bệnh.

Điều trị phầu thuật có thể bằng kết hợp xương (KHX) hoăcc thay khớp háng. Phẫu thuật KHX sử dụng nhiều với nhiều phương pháp khác nhau như: Găm kim, bắt vít, đóng đinh ender, đinh gama... nhằm bất động xương vững, phục hồi tốt về giải phẫu giúp xương liền tốt, tập phục hồi chức năng sớm tránh được các biến chứng toàn thân và sớm trở lại cuộc sống lao động và sinh hoạt. Tuy nhiên ở người già do loãng xương nên $\mathrm{KHX}$ thường bất động không vững, thường phải bất động thêm nên không PHCN sớm, hậu quả bệnh nhân phải nằm lâu, gặp nhiều biến chứng toàn thân kể cả tử vong, đây là mặt tồn tồn tại của phương pháp này.

Để khắc phuc nhược điểm của các phương pháp trên đối với người cao tuổi phẫu thuật thay khớp háng bán phần (Bipolar) được lựa chọn. Nghiên cứu này nhằm mục tiêu: "Đánh giá kêt quả phẫu thuật thay khớp háng bán phần trong điều trị gãy LMCXĐ người cao tuối"

\section{II. ĐỐI TƯợNG VÀ PHƯƠNG PHÁP NGHIÊN CỨU}

- Nghiên cứu mô tả cắt ngang 50 bệnh nhân cao tuổi gãy LMCXĐ tại Bệnh viện Việt Đức từ tháng $1 / 2020$ tới tháng $3 / 2021$

- Tiêu chuẩn lựa chọn bệnh nhân:

+ Bệnh nhân cao tuổi $\geq 70$, gãy LMCXĐ

+ Trước đó đi lại bình thường, không có bệnh nền nặng kèm theo

+ Bệnh nhân đồng ý tham gia nghiên cứu

- Quy trinh kỹ thuât

+ Đánh giá trước mố: Đánh giá toàn trang hô hấp, tuần hoàn, các bệnh phối hợp, XQ kiểm tra mức độ gãy, loãng xương. Chuẩn bị mổ và điều trị các bệnh phối hợp mức độ nhẹ cho đến trung bình nếu có.

+ Quy trình mổ: Gây tê hoặc gây mê, kê tư tế, sát khuẩn vùng mổ, rạch da và bộc lộ vùng gãy, cắt cổ lấy chỏm xương đùi, đo chỏm, ráp ống tuỷ xương đùi, thay khớp háng bán phần không cement, đặt lại khớp và đóng vết mổ. Bất động chi gãy.

+ Hậu phẫu: Điều trị kháng sinh, nội khoa, thay băng vết mổ và tập phục hồi chức năng 
theo phác đồ từ ngày thứ 2 sau mổ.

Đánh giá kêt quả điều trị. Đánh giá chức năng khớp háng theo chỉ số của Merle d'Aubigné - Postel [1]: Mức độ đau, biên độ vận động khớp và khả năng đi bộ (tính theo độ vững) với các mức độ:

17-18 điểm: Rất tốt

15-16 điểm: Tốt

13-14 điểm: Khá

10-12 điểm: Trung bình

$\leq 9$ điểm: Xấu

Đánh giá XQ khớp háng: Sai khớp, vị trí chuôi, mòn ổ cối

- Sử lý số liệu bằng phần mềm thống kê y học: phần mềm SPSS 16.0

- Đạo đức nghiên cứu: Nghiên cứu không ảnh hưởng đến chất lượng điều trị bệnh nhân, các bệnh nhân đồng ý tham.

\section{KẾT QUẢ NGHIÊN CỨU}

3.1. Tuổi, giới. Trong nghiên cứu, có $35 \mathrm{BN}$ nữ $(70 \%)$ và 15 nam $(30 \%)$, tỷ lệ nữ/nam là 2,3 . Độ tuổi trung bình là 80,7 tuổi, thấp nhất là 71 tuổi, cao nhất là 90 tuổi, độ tuổi gặp nhiều nhất là $79-80$ chiếm $85,3 \%$. BN chủ yếu gãy do TNSH chiếm 95,3\%. Tất cả BN liền vết mổ thì đầu

\subsection{Thời gian nằm viện}

Bảng 1: Thời gian nằm viện

\begin{tabular}{|c|c|c|}
\hline Thời gian nằm viện & Số bệnh nhân & $\mathbf{\%}$ \\
\hline < 7 ngày & 40 & 80 \\
\hline $7-10$ ngày & 7 & 14 \\
\hline$>10$ ngày & 3 & 6 \\
\hline
\end{tabular}

Nhận xét: Thời gian nằm viện 5-14 ngày, trung bình 8,2 ngày

\subsection{Biến chứng sớm sau mổ}

Bảng 2: Biến chứng sớm

\begin{tabular}{|c|c|c|}
\hline Biến chứng & $\mathbf{n}$ & $\mathbf{\%}$ \\
\hline Không & 48 & 96 \\
\hline Trật khớp & 1 & 2 \\
\hline Viêm phối, HKTM, loét tỳ đè & 0 & 0 \\
\hline Tim mạch & 1 & 2 \\
\hline Tống số & $\mathbf{5 0}$ & $\mathbf{1 0 0}$ \\
\hline
\end{tabular}

Nhận xét: Có 2 BN biến chứng ớm chiếm 4\%

3.4. Kết quả

Bảng 3: Đánh giá kêt quả chung

\begin{tabular}{|c|c|c|c|c|c|c|}
\hline $\begin{array}{c}\text { Kết } \\
\text { quả }\end{array}$ & $\begin{array}{c}\text { Rất } \\
\text { tốt }\end{array}$ & Tốt & Khá & $\begin{array}{c}\text { Trung } \\
\text { bình }\end{array}$ & Xấu & Tổng \\
\hline $\begin{array}{c}\text { Số } \\
\text { lượng }\end{array}$ & 26 & 16 & 6 & 1 & 1 & 50 \\
\hline $\begin{array}{c}\text { Tỷ lệ } \\
\%\end{array}$ & 52,0 & 32,0 & 12,0 & 2,0 & 2,0 & 100,0 \\
\hline
\end{tabular}

Nhận xét: Kết quả chức năng khớp háng đạt tốt và rất tốt là $84 \%$, khá là $12 \%$.

\section{BÀN LUẬN}

Trong nghiên cứu của chúng tôi đô tuổi trung bình là 80.7 tuổi, thấp nhất là 71 tuổi, cao nhất là 90 tuổi, đây là nhóm bệnh nhân lớn tuổi đều bị loãng xương nhiều nên chỉ cần ngã đập mông nhẹ xuống nền cứng là bị gãy xương. Tỷ lệ nữ/ nam $\approx 2 / 1$. Tỷ lệ này phù hợp với các tác giả khác $[2,3,4]$

Thời gian bệnh nhân nằm viện trung bình 8,2 ngày, trong đó có $94 \%$ nằm viện dưới 10 ngày, bênh nhân nằm viên lâu hơn nhóm bênh khác là do tình trạng sức khỏe yếu, mắc nhiều bệnh toàn thân như các bệnh tim mạch, hô hấp... nên phải điều trị nội khoa trước, trong và sau mổ. Đăc biệt có bệnh nhân trên 14 ngày do phải điều trị toàn thân sau mổ: điều trị cao huyết áp, giảm hô hấp... Thời gian nằm viện của $\mathrm{BN}$ tương tự các tác giả $[3,4]$

Trong nghiên cứu $100 \%$ BN không sảy ra biến chứng trong mổ và liền vết mổ tốt thì đầu. Kết quả này cho thấy sự phát triển ngành hồi sức và kháng sinh nên bệnh nhân được điều trị tốt trước mổ và trong mổ nên hạn chế được tai biến; Bệnh nhân xu hướng ngày càng được phẫu thuật nhiều hơn. Có 1 trường hợp (2\%) trật lại khớp háng do khâu vận chuyển BN không tốt, chỉ cần nắn lại khớp tại khoa khám xương. Có 1 BN (2\%) biến chứng tim mạch do có tiền sử cao huyết áp, COPD. Thời gian nằm viện điều trị kéo dài đến 14 ngày. Không có trường hợp nào biến chứng tim phổi, huyết khối tĩnh mach, loét tỳ đè, cho thấy ưu điểm của phương pháp phẫu thuật thay khớp háng bán phần so với kết hợp xương là giúp người bệnh đi lại sớm, tránh được biến chứng do nằm lâu.

Trong 50 BN không có biến chứng xa có $84 \%$ $B N$ đạt kết quả tốt và rất tốt, $12 \%$ đạt khá, $4 \%$ $B N$ đạt kết quả trung bình và xấu. Kết quả này phù hợp với kết quả nghiên cứu của các tác giả $[2,3,4,5,6]$ cho thấy sự phù hợp của phương pháp vói đối tượng người già bị loãng xương gãy LMCXĐ. Từ đó đưa ra chỉ định thay khớp háng bán phần căn cứ vào các yều tố: người cao tuổi, loãng xương, mắc các bệnh toàn thân, cơ sở chuyên khoa, điều kiện hồi sức trước trong và sau mổ...

\section{KẾT LUẬN}

Nghiên cứu trên 50 BN gãy LMCXĐ người cao tuổi thu được kết quả:

- 4\% BN gặp biến chứng sau mổ: $2 \%$ trật khớp, $2 \%$ biến chứng tim mạch. Không có biến chứng viêm phổi, huyết khối tĩnh mạch hay loét tỳ đè. 
- Kết quả thay khớp: $84 \%$ tốt, 12\% khá

Phẫu thuật thay khớp háng bán điều trị gãy LMCXĐ là một giải pháp tốt cho người già, gãy LMCXĐ loai $A_{1}, A_{2}$.

\section{TÀI LIỆU THAM KHẢO}

1. Merle d'Aubigné R. (1970), "Cotation chiffrée de la fonction de la hanche". Rev Chir Ortho Reparatrice Appar Mot, 56 (5), pp 481-86.

2. Nguyệ̂n Mạnh Khánh, Đoàn Việt Quân, Nguyễn Xuần Thùy "Thay khớp háng bán phần ở bệnh nhân gãy liên mấu chuyển không vững" Tạp chí chấn thương chỉnh hình việt nam số $1-2012$, tr 39-44.

3. Phí Mạnh Công (2009). " Đánh giá kết quả điều trị gãy liên mấu chuyển xương đưi ở người trên 70 tuối bằng kết hợp xương nẹp vít động tại bệnh viện Xanh pôn và bệnh viện 198". Luận văn thạc sĩ $y$ hoc, tr 40-41.

4. Hoàng Thế Hùng (2013). "Đánh giá kết quả điêu tri gãy liên mấu chuyển xương đùi ở người cao tuổi bằng thay khớp háng bán phần bipolar". Luận văn thạc sỹ y học, học viện quân y, tr 50-51.

5. Sancheti K. H., Sancheti P. K., Shyam A. K., Patil S., Dhariwal Q., Joshi R., (2010), "Primary hemiarthroplasty for unstable osteoporotic intertrochanteric fracture in the elderly, a retrospective case series", Indian journal orthropaedic, 44, 428-434.

6. Hong-Man Cho, MD, Seung-Ryul Lee, MD... "Standard Type Cemented Hemiarthroplasty with Double Loop and Tension Band Wiring for Unstable Intertrochanteric Fractures in the Elderly" J Korean Hip Soc 22(2): 159-165, 2010

\title{
SẢN XUẤT THUỐC BẰNG CÔNG NGHÊ IN 3D FDM PHẦN 3: ỨNG DỤNG CÔNG NGHÊ IN 3D FDM TRONG LĨNH VỰC DƯợC PHẨM VÀ NHỮNG THÁCH THỨC
}

\author{
Lê Thị Thu Trang*, Trần Thị Hải Yến*, Võ Quốc Ánh*
}

\section{TÓM TẮT}

In 3D FDM là công nghê bồi đắp từng lớp để tạo thành cấu trúc chi tiết 3 chiều của vật thể với độ chính xác cao. Công nghê mới này mở ra cớ hội sản xuất các thuốc cá nhân hóa hướng tới người bệnh là trung tâm, phục vu nhu cầu điều trị riêng theo khả năng đáp ứng của mổi người bệnh. Đồng thời, công nghệ này cho phép sản xuất các dạng thuốc cấu trúc phức tạp thuốc đa thành phần, hệ nổi, dạng thuốc có kiểm soát giải phóng... Tuy có nhiều tiềm năng, song công nghệ in 3D cũ̃ng gặp phải không ít thách thức khi triển khai thực tiển. Có thể kể đến đó là: khó khăn trong việc nâng quy mô sản xuất, đảm bảo chất lượng và những vấn đề liên quan bản quyền, thủ tục pháp lỳ.

Từ khóa: Công nghệ in 3D, thuốc in 3D, cá nhân hóa điều trị, thuốc kiểm soát giải phóng.

\section{SUMMARY}

\section{OPPORTUNITIES AND CHALLENGES OF FUSED \\ DEPOSITION MODELING 3D PRINTING TECHNOLOGY IN PHARMACEUTICAL FORMULATION DEVELOPMENT}

Fused deposition modeling (FDM) is currently the most popular additive manufacturing technology owing to its flexibility, low cost and ease of use. This technology can fabricate complex objects as well as flexibly customize dosage forms satisfying treatment

*Trường đại học Dược Hà Nội

Chịu trách nhiệm chính: Võ Quốc Ánh

Email: anhvq@hup.edu.vn

Ngày nhận bài: 12.5 .2021

Ngày phản biện khoa họ: 2.7.2021

Ngày duyệt bài: 13.7.2021 needs of patients. Numerous polymer excipients have been studied that offer a wide range of choices for various pharmaceutical dosage forms such as control release, multi API loaded pills, intragastric floating drug delivery systems. However, this emerging technology also faces many challenges related to print quality issues, intellectual property and lack of regulatory guidelines when it comes to the industry.

Keywords: Three-dimension (3D) printing, 3D printed drugs, fused deposition modeling, material extrusion.

\section{I. ĐẶT VẤN ĐỀ}

Ngày nay, hầu hết các thuốc được sản xuất công nghiệp với quy mô lớn và đưa vào sử dụng điều trị đại trà. Thành phần, liều lượng thuốc được tính toán và thiết kế để phù hợp cho sô đông bệnh nhân. Phương pháp "một liều dùng cho tất cả" này gặp phải một số hạn chế về hiệu quả điều trị do sự khác nhau về giới tính, cẩn nặng, đặc điểm di truyền, khả năng chuyển hóa thuốc, môi trường sông, thói quen sinh hoạt giữa những người/nhóm người bệnh. Cùng một chế phẩm thuốc sẽ cho kết quả tốt trên bệnh nhân này, nhưng sẽ không cho kết quả ở bệnh nhân kia, thậm chí gây độc cho vài bệnh nhân khác. Để khắc phục hạn chế đó, "cá nhân hóa điều trị" (personalized treatment) được coi là phương pháp lý tưởng bởi nó lấy cá thể người bệnh làm trung tâm, hướng tới mục tiêu người nào thuốc nấy.

Trong những năm gần đây, sự phát triển khoa học kỹ thuật cùng với công nghệ in 3D đã mở ra cơ hội sản xuất thuốc theo nhu cầu điều 